\title{
RUANG SENI BEBAS STRES TJIKINI
}

\author{
Jessica Santoso ${ }^{1)}$, Sutarki Sutisna ${ }^{21}$ \\ ${ }^{1)}$ Program Studi S1 Arsitektur, Fakultas Teknik, Universitas Tarumanagara, \\ Jesssantoso98@gmail.com \\ 2)Program Studi S1 Arsitektur, Fakultas Teknik, Universitas Tarumanagara, tarkisutisna@gmail.com
}

Masuk: 13-07-2020, revisi: 30-07-2020, diterima untuk diterbitkan: 24-09-2020

\begin{abstract}
Abstrak
Konsekuensi tinggal di kota besar dengan dinamika kehidupannya yang sangat intens menjadikan masyarakat perkotaan rentan mengalami stres dibandingkan mereka yang tinggal di daerah pedesaan. Jakarta menduduki peringkat ke-132 dari 150 kota paling stres di dunia. Tingkat stres masyarakatnya telah memasuki tahap kritis yakni, melebihi stadium lima dari skala 1-10 dan jumlah penderita gangguan mental emosional (stres) yang terus meningkat setiap tahunnya. Banyak faktor yang menjadi penyebab stres masyarakat kota diantaranya, tingginya tingkat urbanisasi, kemacetan, kurangnya ketersediaan ruang terbuka hijau, stres akibat menghadapi beban tuntutan pekerjaan hingga stres akibat tuntutan kehidupan perkotaan yang serba cepat, dinamis, dan serba efisien. Maka dari itu, masyarakat kota membutuhkan tempat ketiga. Sebuah ruang yang menghubungkan rumah atau tempat tinggal (tempat pertama) dan tempat kerja (tempat kedua) sebagai ruang publik yang lebih santai bagi masyarakat kota untuk dapat beristirahat, berhenti sejenak dari segala rutinitas yang dilakukan setiap hari, bersosialisasi dan berinteraksi serta menjadi tempat untuk menyalurkan stres. Dengan menggunakan metode Healing Environment, Ruang Seni Bebas Stres Tjikini bertujuan untuk membuat sebuah ruang publik yang memberikan ruang dan waktu bagi masyarakat kota untuk berkreasi, berekspresi, berkumpul, berinteraksi, dan mengenal lebih luas mengenai seni sebagai salah satu alternatif untuk relaksasi dan menyalurkan stres mereka. Juga sebagai fasilitas pendukung kegiatan seni pada Kawasan Cikini yang akan menjadi Pusat Kesenian Dan Kebudayaan Jakarta.
\end{abstract}

Kata kunci: Interaksi; Stres; Stres Perkotaan; Tempat Ketiga

\begin{abstract}
The consequences of living in a big city with such an intense life pace putting the citizens at higher risk for stress compared to those who live in the rural areas. Jakarta ranked $132^{\text {nd }}$ out of 150 in the world's most stressfull cities ranking. The stress level of its citizens is at level five on a scale of 1-10 and the numbers of its population with mental health problem keeps increasing each year. There are several factors that contribute to stress, i.e. the high rate of urbanization, traffic congestion, the lack of green spaces availability, heavy workload and also the pace of life in cities that needs us to always be faster, dynamic and efficient. Therefore, those who live in the cities needs the third place. A comfier space between home (first place) and work (second place) for citizens to spend the time, to take a break from the daily routine, to socialize and to interact with others, and also as a place to relieve the stress. Using the healing environment approach, the purpose of Tjikini Stress Relieve Art Space is to provide an urban public space for recreation, freedom of expression, social gathering, social interaction and to have better knowledge on the arts as one of the alternatives to relax and to relieve the stress. It also acts as an supporting facility for arts activities in Cikini area which will become art and culture center of Jakarta.
\end{abstract}

Keywords: Interaction; Stress; Third Place; Urban Stress 


\section{PENDAHULUAN}

Konsekuensi tinggal di kota besar salah satunya adalah berurusan dengan stres. Permasalahan kota seperti tingginya tingkat urbanisasi, faktor ekonomi, kemacetan, kurangnya ketersediaan ruang terbuka hijau, polusi udara, kesenjangan sosial dan ras, beban tuntutan pekerjaan hingga tuntutan kehidupan perkotaan yang serba cepat, dinamis, dan serba efisien menyebabkan masyarakat perkotaan lebih rentan mengalami stres dibandingkan dengan mereka yang tinggal di pedesaan. Hasil penelitian dari Zipjet dalam "The 2017 Global Least and Most Stressful Cities Ranking" menunjukkan bahwa, Jakarta menduduki peringkat ke-132 dari 150 kota paling stres di dunia. Menurut data Litbangkes Kemenkes prevalensi gangguan mental emosional (stres) DKI Jakarta telah mencapai $4,4 \%$ dengan jumlah penderita stres yang terus meningkat setiap tahunnya. Tingkat stres masyarakat DKI Jakarta telah memasuki tahap kritis, yakni melebihi stadium lima dari skala 1-10. Stres memang dialami secara umum oleh penduduk kota-kota besar di dunia. Merujuk dari tulisan "The World is Flat", semakin lama wajah kota besar akan semakin sama. Kesamaan tersebut berkaitan dengan wilayah yang semakin datar, padat, ramai, lingkungan gerak yang sempit, serta dinamika kehidupan yang sangat intens.

Faktor-faktor inilah yang membuat penduduk kota-kota besar di dunia menjadi lebih mudah terpengaruh oleh stres. Stres dapat berkembang menjadi gejala yang lebih akut, yaitu depresi dan dapat mempengaruhi tingkat produktivitas hingga memunculkan gangguan sosial.Ditengah semakin padat dan semakin banyaknya masalah perkotaan yang muncul di kota Jakarta dan menyebabkan peningkatan stres secara terus-menerus, dibutuhkan sebuah tempat ketiga atau Third Place sebagai sebuah ruang publik yang mewadahi kehidupan publik yang informal, menyenangkan, memberikan ruang dan waktu untuk berkreasi, berekspresi, berkumpul, dan berinteraksi bagi masyarakat. Namun, sekarang ini umumnya tempat publik yang mewadahi suatu kegiatan tertentu akan didominasi oleh kegiatan komersil yang memiliki fungsi utama untuk menjual produk atau pelayanan dengan mendapatkan keuntungan, dan tidak secara khusus bertujuan untuk menyediakan ruang bagi masyarakat untuk menetap lama, bersosialisasi, dan berkomunitas. Tujuan dari proyek ini adalah untuk melayani masyarakat kota Jakarta yang semakin bersifat individualis akibat minimnya tempat publik inklusif yang dapat mewadahi kegiatan mereka untuk dapat saling berinteraksi, berkomunitas secara informal, dan mengenal lebih luas mengenai seni sebagai salah satu alternatif untuk relaksasi dan menyalurkan stres mereka.

\section{KAJIAN LITERATUR}

\section{Third Place}

Menurut Ray Oldenburg dalam The Great Good Place $(1989,1991)$, "tempat pertama" seseorang adalah rumah atau tempat tinggal. "Tempat kedua" adalah tempat kerja, tempat di mana kebanyakan orang mungkin menghabiskan sebagian besar waktu mereka. Sedangkan "Tempat ketiga" atau Third Place dapat diartikan sebagai "jangkar" kehidupan komunitas, tempat dimana kita dapat relax, beristirahat, dan berhenti sejenak memikirkan masalah kehidupan yang muncul setiap harinya. The Third Place di dalam konteks perkotaan merupakan sebuah program yang akan membantu masyarakat kota agar bersifat lebih humanis didalam kebutuhan mereka yang menuntut kehidupan yang serba cepat, dinamis, dan efisien. Karateristik tempat ketiga, antara lain:

a. Bersifat netral, yaitu setiap pengunjungnya memiliki kedudukan yang sama, tidak ada hierarki maupun status.

b. Inclusive (memiliki status dan hak yang sama), sifat ini diperlukan untuk membuka kemungkinan terjadinya interaksi dan komunikasi antar sesama manusia tanpa melihat atribut keseharian seperti, jabatan, latar belakang budaya hingga status marital. 
c. Percakapan adalah kegiatan utama.

d. Aksesibilitas dan akomodasi, tempat ketiga sebagai bagian dari komunitas harus mudah dijangkau dan mengakomodir lingkungan sekitarnya.

e. Pengunjung reguler, tempat ketiga merupakan bagian dari komunitas suatu kelurahan atau desa sehingga pengunjung yang datang adalah masyarakat sekitar, namun tidak menutup kemungkinan bagi pengunjung baru untuk bergabung.

f. Profil rendah, agar masyarakat yang datang tidak memiliki keraguan juga menunjukkan bahwa tempat ketiga adalah tempat bagi siapapun tanpa terkecuali.

g. Perasaan / pembawaan yang menyenangkan, tempat ketiga bukan hanya sebagai tempat berkumpul bagi masyarakat melainkan tempat dimana masyarakat dapat menemukan kegembiraan dalam kebersamaan.

\section{Open Architecture}

Menurut Suryono Herlambang, Open Architecture merupakan bagian dari Open Society dimana kehidupan diperkotaan besar umumnya akan membuat kita cenderung bertemu dengan banyak orang sehingga diperlukan sifat toleransi dan inklusifitas agar dapat menghasilkan Open City sebagai kota yang aman bagi orang-orang untuk dapat bertumbuh secara berdampingan dengan baik. Open Architecture sendiri memiliki prinsip "a lot to do with emphaty" (Herman Hertzberger, 2016) yang berarti sang arsitek sendiri harus benarbenar mengerti tentang bangunan yang akan dirancangnya dan dapat merasakan kegiatan apa yang akan berlangsung didalamnya.

Open Architecture for The Third Place sendiri memiliki pengertian sebagai permeable space yang menghubungkan tempat pertama berupa tempat tinggal dan tempat kedua berupa tempat kerja sebagai ruang sosial yang lebih santai bagi masyarakat kota untuk saling berinteraksi, bertukar informasi, bersantai, menikmati waktu kebersamaan dengan orang sekitar mereka, bertemu orang baru sehingga dapat tercipta komunitas yang kuat, menciptakan empati di antara orang-orang, mempertahankan pandangan tentang diri sendiri sebagai bagian dari sesuatu yang lebih besar serta memiliki sifat humanis terbuka, dinamis, juga produktif.

\section{Stres}

Menurut Santrock (2003), stres adalah respon individu terhadap keadaan atau kejadian yang memicu stres (stressor), yang dapat mengancam dan mengganggu kemampuan seseorang untuk menanganinya (coping). Stres adalah reaksi tubuh yang muncul saat seseorang mengahadapi ancaman, tekanan, atau suatu perubahan. Stres juga dapat terjadi karena situasi atau pikiran yang membuat seseorang merasa putus asa, gugup, marah, atau bersemangat. Schafer (2000) menggolongkan stres menjadi tiga golongan atas dasar persepsi individu terhadap stres yang dialaminya yaitu: Eustress (stres poisitif), Distress (stres negatif), dan Neustress (stress netral).

Tabel 1. Hubungan antara Sindrom Stres, Level Stres, Gejala, Cara Mengatasi, dan Jenis

\begin{tabular}{|c|c|c|c|c|}
\hline \multicolumn{5}{|c|}{ Terapi } \\
\hline Sindrom Stres & $\begin{array}{l}\text { Level } \\
\text { Stres }\end{array}$ & Gejala/ Keluhan & Cara Mengatasi & Jenis Terapi \\
\hline $\begin{array}{l}\text { Tahap I } \\
\text { Alarm Stage }\end{array}$ & Tahap I & $\begin{array}{l}\text { Merasa senang, over } \\
\text { acting, merasa mampu } \\
\text { menyelesaikan pekerjaan } \\
\text { dengan cadangan energi } \\
\text { yang menipis }\end{array}$ & $\begin{array}{l}\text { Berkumpul, } \\
\text { menenangkan diri, } \\
\text { berlatih fisik }\end{array}$ & Terapi fisik \\
\hline
\end{tabular}




\begin{tabular}{|c|c|c|c|c|}
\hline & Tahap II & $\begin{array}{l}\text { Mulai hilang rasa bahagia, } \\
\text { letih sewaktu bangun pagi, } \\
\text { lelah sesudah makan siang, } \\
\text { jantung berdebar-debar, } \\
\text { otot punggung tegang, } \\
\text { tidak bisa santai }\end{array}$ & $\begin{array}{l}\text { Menenangkan } \\
\text { pikiran, bersantai, } \\
\text { melawan rasa lelah }\end{array}$ & $\begin{array}{l}\text { Terapi musik, } \\
\text { Terapi warna }\end{array}$ \\
\hline \multirow[t]{3}{*}{$\begin{array}{l}\text { Tahap } 2 \\
\text { The Stage of } \\
\text { Resistance }\end{array}$} & $\begin{array}{c}\text { Tahap } \\
\text { III }\end{array}$ & $\begin{array}{lr}\text { Gangguan } & \text { usus, } \\
\text { lambung } & \text { (gastritis, } \\
\text { diare), } & \text { tegang otot }\end{array}$ & $\begin{array}{l}\text { Meningkatkan } \\
\text { konsentrasi, } \\
\text { menenangkan diri, }\end{array}$ & $\begin{array}{l}\text { Relaksasi, } \\
\text { meditasi, } \\
\text { terapi }\end{array}$ \\
\hline & & $\begin{array}{l}\text { Makin terasa, meningkatnya } \\
\text { emosional, insomnia, sistem } \\
\text { koordinasi terganggu } \\
\text { (pingsan) }\end{array}$ & berlatih fisik & mandala \\
\hline & $\begin{array}{l}\text { Tahap } \\
\text { IV }\end{array}$ & $\begin{array}{l}\text { Sulit bertahan hingga waktu } \\
\text { sehari, pekerjaan makin } \\
\text { membosankan dan sulit, } \\
\text { tidak mampu merespon } \\
\text { secara memadai, sikap } \\
\text { Negativisme } \\
\text { bergairah), } \\
\text { daya ingat dan konsentrasi, } \\
\text { takut, dan cemas tanpa } \\
\text { sebab }\end{array}$ & $\begin{array}{l}\text { Meningkatkan } \\
\text { konsentrasi, } \\
\text { meningkatkan } \\
\text { metabolisme tubuh }\end{array}$ & \\
\hline \multirow[t]{2}{*}{$\begin{array}{l}\text { Tahap } 3 \\
\text { The Third and } \\
\text { The Final } \\
\text { Stage/ The } \\
\text { Exhaustion Stage }\end{array}$} & $\begin{array}{l}\text { Tahap } \\
\text { V }\end{array}$ & $\begin{array}{l}\text { Physical andPsychological } \\
\text { exhaustion, tidak mampu } \\
\text { menyelesaikan pekerjaan } \\
\text { ringan dan sederhana, gastro } \\
\text { intestinal disorder, } \\
\text { peningkatan rasa takut, } \\
\text { cemas, mudah bingung, } \\
\text { Merokok }\end{array}$ & $\begin{array}{l}\text { Meningkatkan } \\
\text { konsentrasi, } \\
\text { meningkatkan } \\
\text { metabolisme tubuh, } \\
\text { konsvultasi }\end{array}$ & $\begin{array}{l}\text { Relaksasi, Art } \\
\text { Therapy, } \\
\text { konsultasi, } \\
\text { penanganan } \\
\text { medis }\end{array}$ \\
\hline & $\begin{array}{l}\text { Tahap } \\
\text { VI }\end{array}$ & $\begin{array}{l}\text { Jantung berderbar sangat } \\
\text { kencang, susah bernfas, } \\
\text { badan gemetar, dingin, dan } \\
\text { keringat bercucuran, } \\
\text { ketiadaan } \\
\text { tenaga, pingsan }\end{array}$ & $\begin{array}{l}\text { Menurunkan denyut } \\
\text { jantung, } \\
\text { menenangkan diri, } \\
\text { melakukan kegiatan } \\
\text { santai, konsultasi }\end{array}$ & $\begin{array}{l}\text { Konsultasi, } \\
\text { perawatan }\end{array}$ \\
\hline
\end{tabular}

Sumber: Setiadi, 2019

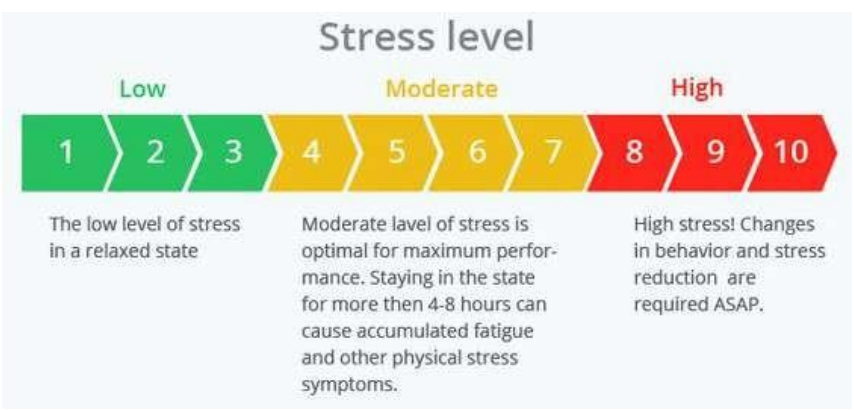

Gambar 1. Tingkatan Stres

Sumber: Jagat Review, 2015 
Berdasarkan hasil penelitian tahun 2007 terhadap pasien di pusat kesehatan masyarakat (puskesmas) se-Jakarta tingkat stress warga Jakarta sudah memasuki tahap kritis, yakni melebihi stadium lima dari skala 1-10. Dan cara menanggulangi stres dapat dilakukan dengan art therapy, terapi fisik (olah gerak), meditasi, terapi musik, terapi warna, dan seni visual.

\section{Art Therapy}

Art Therapy adalah sebuah teknik terapi dengan menggunakan media seni, proses kreatif, dan hasil dari seni untuk mengeksplorasi perasaan, konflik emosi, meningkatkan kesadaran diri, mengontrol perilaku dan adiksi, mengembangkan kemampuan sosial, meningkatkan orientasi realitas, mengurangi kecemasan, mereduksi tingkat stres, dan meningkatkan penghargaan diri (American Art Therapy Association, 2013).

\section{Terapi Warna}

Jane Struthers (dalam Harini, 2013) menjelaskan bahwa terapi warna adalah teknik mengobati penyakit melalui penerapan warna, agar tubuh tetap sehat dan memperbaiki keseimbangan di dalam tubuh sebelum hal itu menimbulkan masalah fisik maupun mental. Warna memiliki gelombang energi yang dapat mempengaruhi psikologis manusia dengan efek yang berbeda-beda. Menurut ilmuwan dari Thomas Jefferson University Philadelphia, terapi warna dapat menyingkirkan masalah stres.

\section{Five Ways to Wellbeing - Ruben Seetharamdoo Phd.}

Ada banyak hal yang dapat dilakukan untuk meningkatkan kesehatan mental seseorang dalam kehidupan sehari-hari maupun dalam keadaan stres. Five Ways to Wellbeing mencakup beberapa pendekatan yang dapat digunakan dalam menjaga kesehatan mental, antara lain; connect dimana berinteraksi secara langsung dengan orang sekitar merupakan salah satu cara untuk mencegah stres bagi semua kalangan usia, be active kegiatan berolahraga/bergerak secara rutin dapat mempengaruhi tingkat stres dan kecemasan seseorang, take notice meningkatkan kepedulian terhadap lingkungan sekitar, mencoba hal-hal baru, menyadari pikiran dan perasaan dapat mengurangi perasaan cemas dan stres seseorang, keep learning menurut Univeristy of Sussex membaca dapat menurunkan tingkat stres seseorang hingga $68 \%$, dan Give orang yang ikut serta dalam kegiatan sosial, komunitas, berkumpul, dan berinteraksi dengan orang lain terbukti memiliki tingkat kebahagiaan yang lebih tinggi dibandingkan orang yang memiliki sifat egoistik.

\section{METODE}

Program dan pendekatan arsitektur yang digunakan adalah Healing Environment, dimana desain arsitektural digunakan sebagai media untuk mereduksi stres. Menurut Knecht (dalam Tedjamulja, 2019), Healing Environment adalah pengaturan fisik dan dukungan budaya yang memelihara fisik, intelektual, sosial, dan kesejahteraan spiritual pasien, keluarga, dan staf karena membantu mereka mengatasi stres terhadap penyakit dan rawat inap. Healing Environment merupakan sebuah lingkungan yang dirancang untuk menciptakan keharmonisan antara pikiran, tubuh, dan jiwa. Unsur- unsur penting dalam penerapan healing environment untuk menjaga psikologis pengguna antara lain; alam dan panca indera. Penerapan healing environment pada objek perancangan berupa penggunaan tanaman peneduh dan tanaman aromaterapi yang dapat menenangkan jiwa dan pikiran pada roof garden juga di dalam ruangn untuk memberikan suasana hijau dan memberi kesan menyatu dengan alam. 

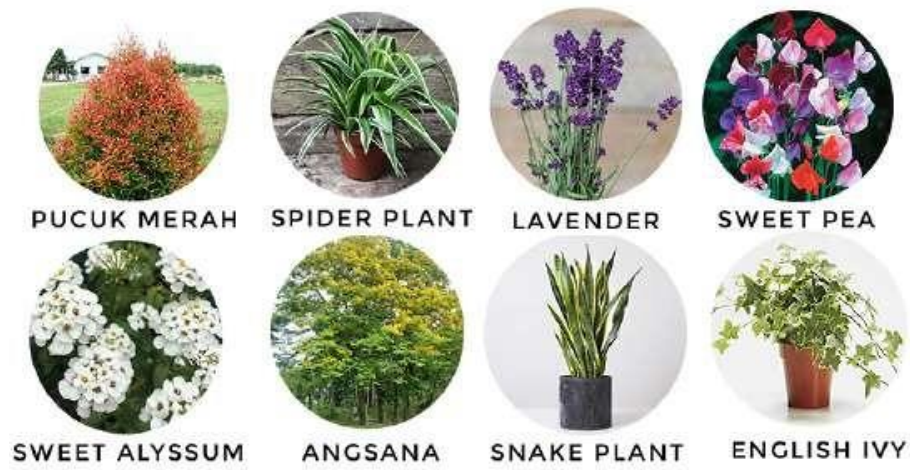

Gambar 2. Jenis Tanaman Peneduh dan Tanaman Aromaterapi

\section{DISKUSI DAN HASIL Analisis Program Kegiatan}

Berdasarkan hasil tinjauan mengenai stres dan cara mereduksi stres melalui Art Therapy/ Terapi Seni, maka terbentuklah program kegiatan yang mendukung proses penyaluran stres. Program kegiatan terbagi menjadi tiga kategori kegiatan, yaitu: Art Therapy, Healing Environment, dan Five Ways to Wellbeing.

\section{Art Therapy}

Art Jamming

Art Jamming pada dasarnya adalah sebuah kegiatan dimana sekelompok orang berkumpul dan mengeksplorasi sisi kreatif mereka dengan mencoba melukis diatas canvas ataupun media lainnya seperti baju, tote bag, dan lainnya. Beberapa orang mungkin akan kurang percaya diri secara artistik dan enggan menampilkan kemampuan kreatif mereka di ruang publik. Namun, Art Jamming secara khusus diciptakan untuk memperhitungkan hal ini dan mencakup semua tingkat bakat dan semua orang dari segala usia.

\section{Splat Paint}

"Splatter painting" atau "Drip Painting" atau "Action Painting" merupakan teknik untuk meggunakan kuas dan peralatan lainnya untuk mengibaskan, melempar, atau meneteskan cat ke permukaan lukisan maupun dinding alih-alih melukis dengan kuas untuk membuat sebuah lukisan. Tidak seperti seni visual lainnya Splat Paint dibuat dengan penuh spontanitas, improvisasi, dan pendekatan fisik untuk membuat seni, sehingga tidak diperlukan pelatihan formal. Orang-orang dapat mengekspresikan diri, bermain, menyalurkan stres maupun mengenal tentang seni secara bebas.

\section{Seni Digital Interaktif}

Merupakan sebuah karya seni yang dipadukan dengan beragam teknologi mulai dari sensorik hingga gerakan. Karya seni ini dibuat didalam sebuah ruangan dengan menggunakan teknologi dan projector untuk menciptakan karya seni visual. Program ini dapat digunakan sebagai sarana relaksasi maupun edukasi secara tidak langsung bagi pengunjung yang datang mengenai seni.

\section{Mural}

Taman Ismail Marzuki (TIM) yang terletak di Kawasan Cikini adalah salah satu pusat kesenian di Jakarta yang merangkap juga sebagai tempat rekreasi visual. Hal itu dikarenakan TIM sering menjadi sarana terjalinnya interaksi antara estetika mural dengan publik dari segala usia dan kalangan. Oleh karena itu, program ini dibuat untuk mendukung program menata ruang publik yang akan dilakukan mendatang di kawasan Cikini dan sebagai sarana interaksi visual masyarakat dengan karya seni. 


\section{Healing Environment}

\section{Roof Garden}

Menurut Journal of Phsysiological Anthropolgy, berinteraksi dengan tanaman atau sekedar menghabiskan waktu di alam terbuka atau sekedar melihat tumbuhan hijau dapat mereduksi tingkat stres dan mengurangi ketegangan.

\section{Five Ways to Wellbeing}

a. Area Yoga

Yoga merupakan salah satu aktivitas olah tubuh dan pikiran yang fokus pada kekuatan, fleksibilitas dan pernapasan untuk meningkatkan kualitas mental dan fisik.

b. Ruang Baca

Peneliti Inggris di University of Sussex menemukan, membaca enam menit sehari lebih ampuh untuk menurunkan tingkat stres hingg $68 \%$ ketimbang jalan-jalan atau sekadar nongkrong di kedai kopi. Membaca juga ternyata memiliki efek menyenangkan yang sama dengan beryoga.

Selain tiga kategori kegiatan diatas, juga terdapat galeri seni sebagai tempat pameran karya seni bagi seniman maupun kalangan mahasiswa untuk memamerkan karya mereka, art store, area healthy food, dan ruang komunal yang digunakan sebagai meeting point, tempat berkumpul bagi masyarakat sekitar untuk dapat beristirahat, berinteraksi, bersosialisasi, dan menikmati acara Live Music secara bebas.

\section{Konsep}

Perancangan ini menggunakan konsep "Out of Stress by Art" dimana seni menjadi salah kunci utama dalam proses penyaluran stres. Selain seni, bangunan ini juga menerapkan pola Biophilic Design yang bertujuan menggunakan alam sebagai salah satu media untuk mereduksi stres. Berdasarkan jurnal 14 Patterns of Biophilic Design oleh TERRAPIN Bright Green (dalam Romadhani \& Suryawan, 2017) menyebutkan bahwa biophilic design dapat membantu mereduksi stres pada seseorang. Terdapat 14 pola yang dapat diterapkan pada perancangan dan dikategorikan sebagai berikut: Nature in Space Pattern (membahas tentang kehadiran langsung dan fisik dari alam seperti tanaman, air, hewan, angin, suara, aroma, dan elemen alam lainnya ke dalam suatu ruangan), Natural Analogues Pattern (membahas organik, non-hidup, dan pembangkitan tidak langsung dari alam seperti benda, bahan, warna, bentuk, urutan, dan pola yang ditemukan dialam, bermanifestasi sebagai karya seni, ornamen, furnitur, dekorasi, dam tekstil pada lingkungan rancangan), dan Nature of Space Pattern (membahas konfigurasi spasial yang berada dialam)

\section{Proses Gubahan Massa}

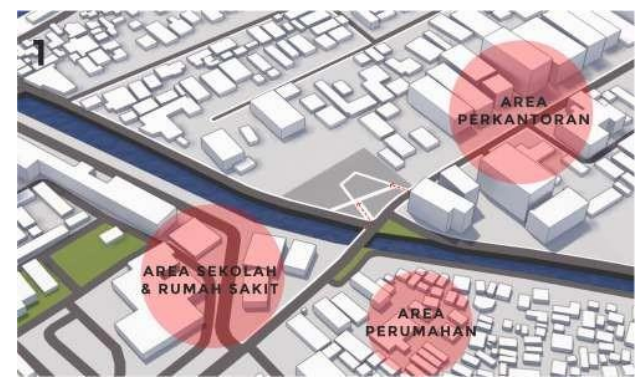

Gambar 3. Pedestrian Flow Axis

Sumber: Penulis, 2020

Groundfloor dibuat terbuka dengan mengutamakan pada user pedestrian yang berasal dari lingkungan sekitar tapak. Groundfloor dijadikan sebagai titik permeabilitas (konsep utama dalam sebuah Third Place). 


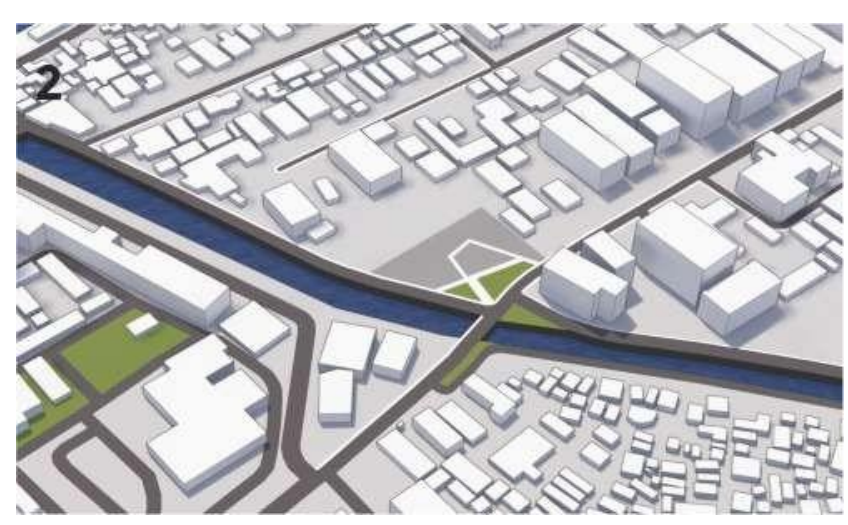

Gambar 4. Extending Greenbelt

Sumber: Penulis, 2020

Menambahkan flow greenbelt pada tapak dari lingkungan sekitar yang akan dijadikan sebagai area komunal. Juga sebagai tamabahan area hijau yang sudah semakin minim akibat perubahan peruntukkan lahan menjadi bangunan perkantoran, pemukiman, maupun sebagai lahan parkir.

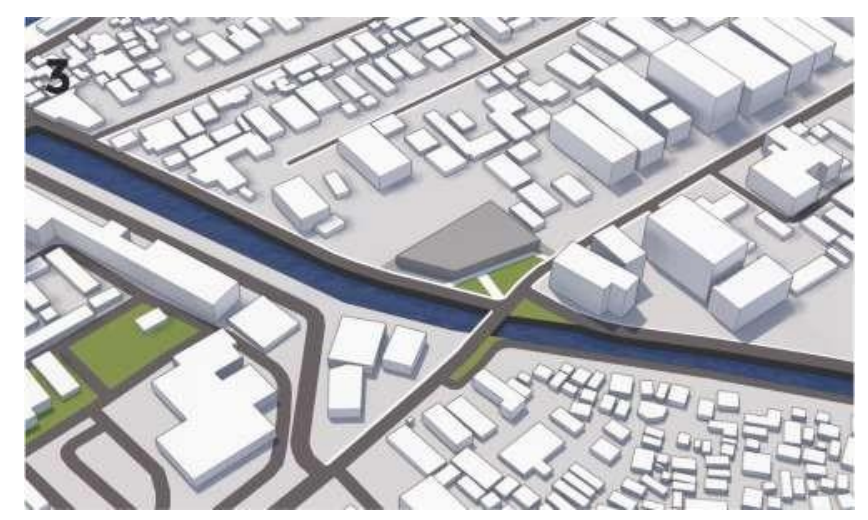

Gambar 5. Mass Placement

Sumber: Penulis, 2020

Bentuk bangunan disesuaikan dengan bentuk tapak dan setback peraturan GSB kota.

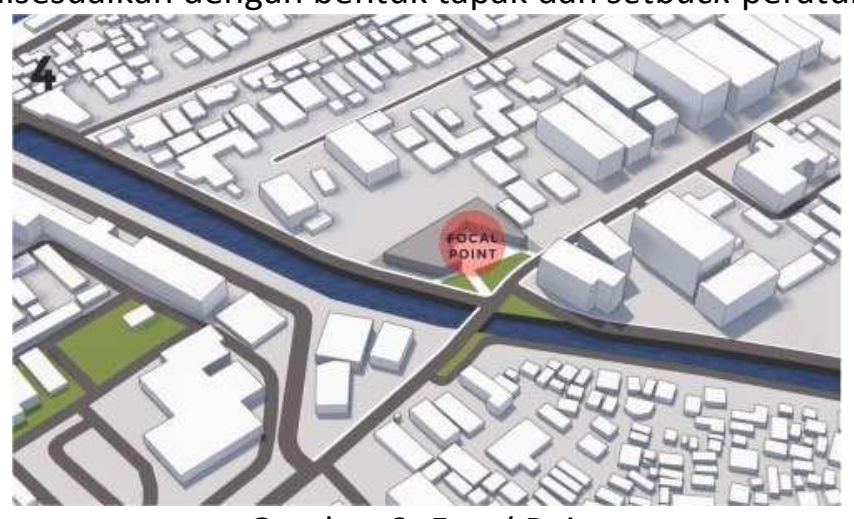

Gambar 6. Focal Point

Sumber: Penulis, 2020

Bagian tengah massa bangunan dipotong untuk menghasilkan sebuah ruang yang akan menjadi fokus bangunan dan sebagai tempat berkumpul bagi publik. 


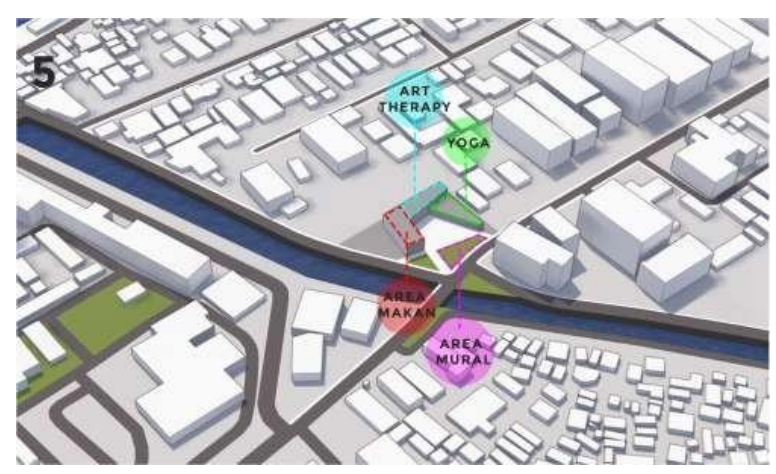

Gambar 7. Zoning

Sumber: Penulis, 2020

Massa bangunan dibagi menjadi tiga kategori kegiatan, yaitu: Art Therapy (berupa program Art Jamming, Splat Paint, Seni digital Interaktif, dan Mural), Healing Environment (berupa Roof Garden), dan Five Ways to Wellbeing (berupa program area Yoga dan Ruang Baca). Juga beberapa program penunjang lainnya seperti Galeri Seni, Art Store, area Healthy Food, dan ruang komunal berupa Amphitheater.

\section{Keunggulan Desain}

Biophilic Design

Penerapan pola-pola biophilic design pada rancangan yang bertujuan untuk membantu mereduksi stres pada seseorang, antara lain:

a. Connection with Natural System

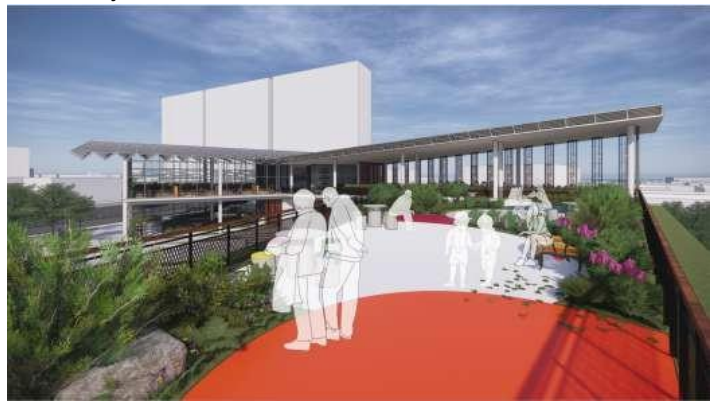

Gambar 8. Roof Garden

Sumber: Penulis, 2020

Pola ini diterapkan pada area roof garden dan taman-taman yang terbuka sehingga masyarakat dapat merasakan kehadiran alam dan menyatu dengan alam secara langsung.

b. Material Connection with Nature

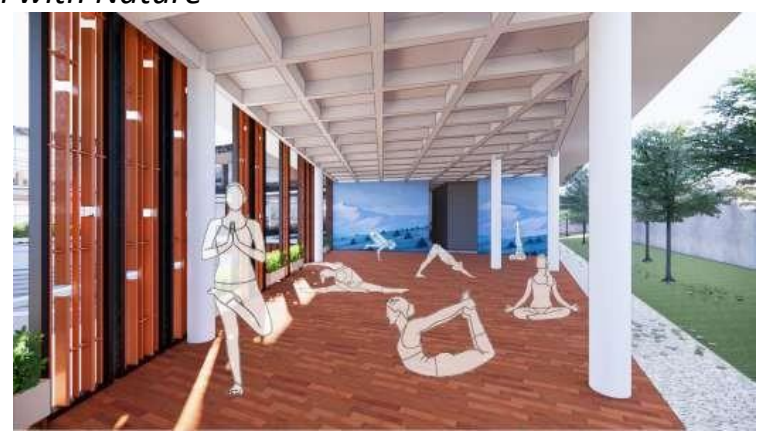

Gambar 9. Area Yoga

Sumber: Penulis, 2020 
Penerapan pola ini berupa penggunaan material-material yang berasal dari alam seperti kayu. Menurut Penelitian dari University of Tampere kayu memiliki efek menenangkan yang didasarkan pada pengalaman emosional positif yang disebabkan oleh kayu, seperti kedekatan dengan alam, kehangatan, kesederhanaan, dan efek relaksasi juga dapat mengurangi tingkat stres.

c. Visual Connection with Nature

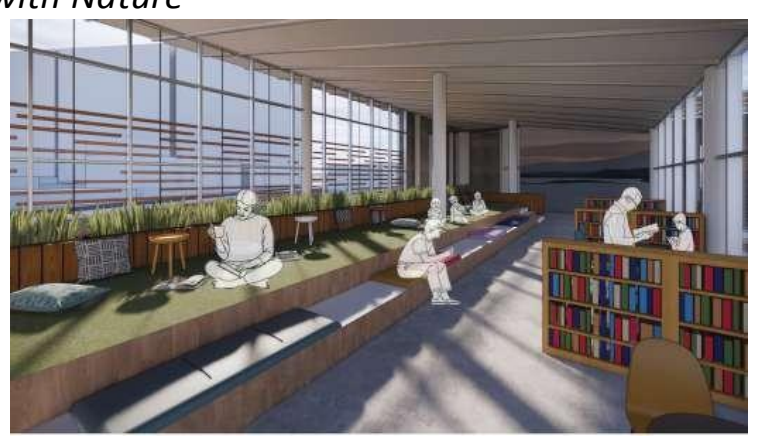

Gambar 10. Area Ruang Baca

Sumber: Penulis, 2020

Menerapkan konsep terbuka dengan banyak bukaan dan transparansi yang memudahkan akses visual dari dalam bangunan ke area taman. Sehingga meskipun orang berada di dalam ruangan tetap dapat merasakan secara visual suasana alam yang di hadirkan pada obyek rancangan.

d. Non-Visual Connection with Nature

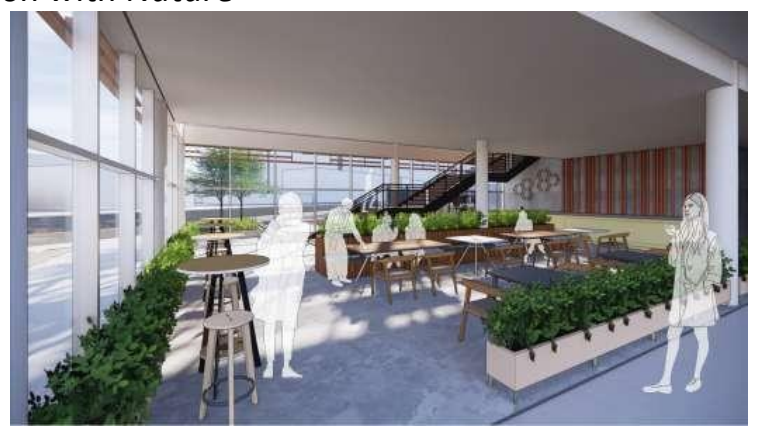

Gambar 11. Area Healthy Food

Sumber: Penulis, 2020

Menghadirkan elemen-elemen alam seperti tanaman dalam pot, air, bebatuan, dan elemen alam lainnya sehingga menghasilkan spasial ruang yang menyatu dengan alam.

e. Presence of Water

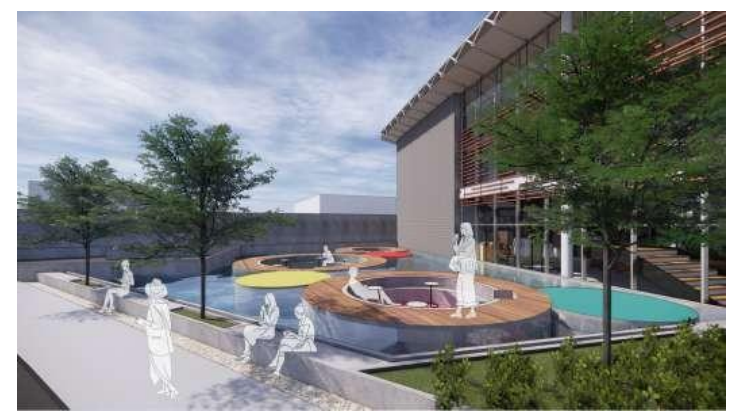

Gambar 12. Area duduk Outdoor Sumber: Penulis, 2020 
Menghadirkan unsur air ke dalam obyek rancangan berupa kolam-kolam dan air mancur. Menurut prinsip healing environment suara air mengalir dapat memberikan efek menenangkan pada orang yang sedang merasa stres.

\section{f. Dynamic \& Diffuse Light}

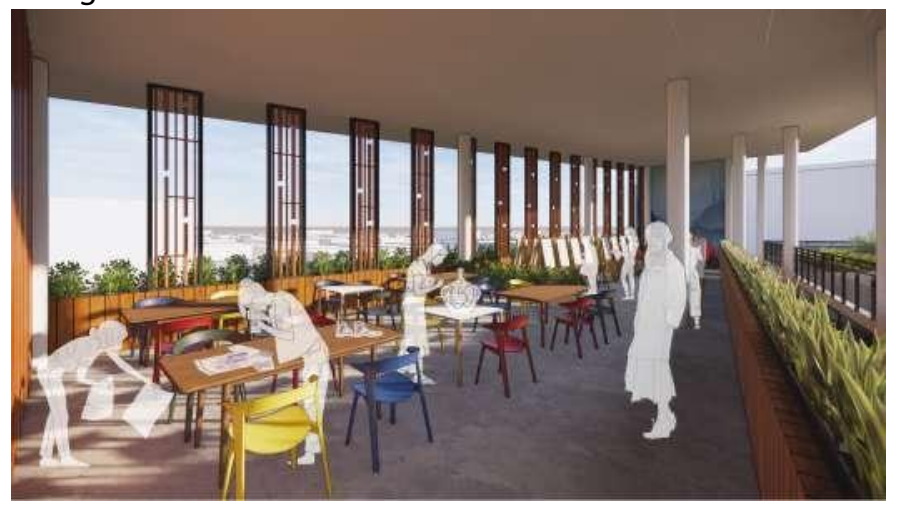

Gambar 13. Area Art Jamming

Sumber: Penulis, 2020

Pengudaraan dan pencahayaan alami merupakan salah satu unsur penting dalam mereduksi tingkat stres seseorang. Pola ini diterapkan dengan memaksimalkan bukaan, beberapa ruangan didesain tanpa dinding dan hanya menggunakan kisi-kisi kayu maupun tanaman sebagai pembatas. Ruangan-ruangan pada bangunan ini tidak memerlukan AC (Air Conditioner) dan mendapatkan banyak cahaya matahari yang masuk ke dalam bangunan sehingga dapat menghemat penggunaan energi.

\section{Ruang Komunal}

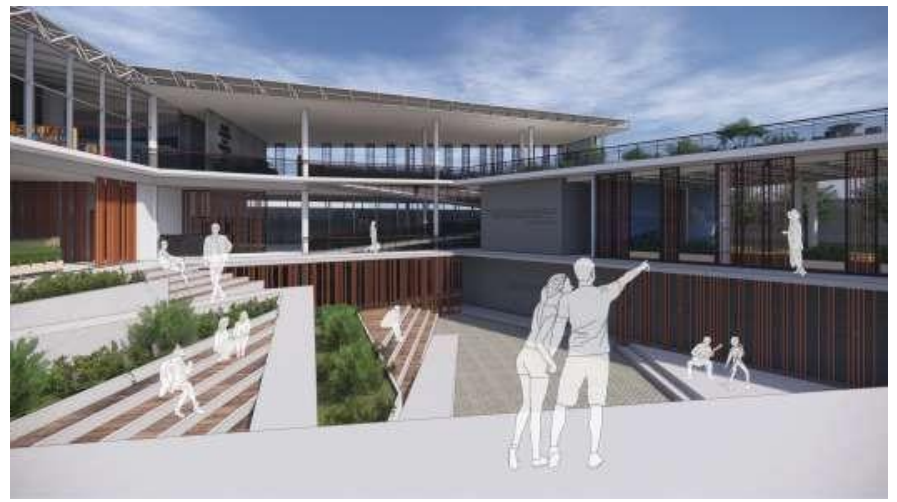

Gambar 15. Amphitheater

Sumber: Penulis, 2020

Pada bagian tengah massa bangunan terdapat ruang komunal berupa amphitheater yang dijadikan sebagai meeting point, tempat berkumpul bagi masyarakat sekitar untuk dapat beristirahat, berinteraksi, bersosialisasi, dan menikmati acara live music secara bebas, juga sebagai titik permeabilitas yang menyatukan bangunan dengan lingkungan sekitarnya.

\section{KESIMPULAN DAN SARAN}

Ditengah semakin padat dan semakin banyaknya masalah perkotaan yang muncul di kota Jakarta menyebabkan bertambahnya peningkatan penderita gangguan mental emosional (stres) setiap tahunnya. Salah satu faktor yang mempengaruhi dikarenakan kurangnya ruang publik inklusif yang dapat mewadahi kegiatan masyarakat kota untuk dapat saling berinteraksi, bersosialisasi, beristirahat dari rutinitas yang melelahkan, dan kurangnya 
ruang publik yang mewadahai aktivitas- aktivitas yang dapat mereduksi tingkat stres mereka. Arsitektur dan seni memiliki andil dalam proses penyaluran stres. Sebuah ruangan dapat mempengaruhi persepsi manusia secara visual dan psikologis. Orang yang lebih sering terpapar udara segar atau berada diluar ruangan memiliki kadar hormon stres yang lebih rendah dibandingkan orang yang menghabiskan waktunya berada didalam ruangan.

Oleh karena itu, proyek ini dirancang dengan menggunakan pendekatan healing environment, dan menerapkan prinsip-prinsip biophilic design yang menggabungkan arsitektur dan alam untuk membantu meredakan rasa penat dan stres. Selain itu, proyek ini juga memberikan wadah bagi masyarakat perkotaan untuk dapat saling berinteraksi, bersosialisasi, berekspresi, dan mengenal lebih mengenai seni yang dapat dimanfaatkan sebagai salah satu alternatif dalam mengurangi tingkat stres mereka. Rancangan ini masih membutuhkan penyempurnaan. Adanya penambahan program-program lain di dalam bangunan yang dapat mendukung proses penyaluran stres. Meningkatkan kualitaskualitas ruangan sehingga dapat memaksimalkan kenyamanan pengguna dalam melakukan aktivitas dan mencapai tujuan untuk membantu masyarakat kota dalam mereduksi tingkat stres dan memperoleh kualitas hidup yang lebih baik.

\section{REFERENSI}

American Art Therapy Association. (2013). American Art Therapy Association. Retrieved February 16, 2020, from https://arttherapy.org

Green, T.B.. (2014). 14 Patterns of Biophilic Design. New York.

Harini, N. (2013). Terapi Warna untuk Mengurangi Kecemasan. Jurnal Ilmu Psikologi Terapan, 1(2), 291-303

Oldenburg, R. (1989). The great good place. Philadelphia: Da Capo Press.

Romadhani, I. \& Suryawan, Wawan A. (2017). Desain Ruang Relaksasi untuk Stres di Perkotaan dengan Penerapan Biophilic Design. Jurnal Sains dan Seni POMITS, 6(2), 2337-3520.

Santrock, J. (2003). Adolescene Perkembangan Remaja, edisi keenam. Jakarta:Erlangga Schaller, B. (2012). Architectural Healing Environments.

Seetharamdoo, R. S. (2018). 5 1 \% Ways to Well-Being: A Comprehensive Lifestyle Medicine Prescription to Optimise Your Psychological Health, Prevent Disease and Live with Vitality and Joy. UK: Balboa Press

Setiadi, P. (2019). Pusat Penyembuhan Orang Stres di Cikini. Jurnal Sains, Teknologi, Urban, Perancangan, Arsitektur (Stupa), 1(2), 1257-1272.

Schafer, W. (2000). Stress management for wellness. Fourth edition. Wadsworth: Belmont California

Tedjamulja, A. L. (2019). Pusat Rehabilitasi Kaum Milenial Depresi di Jagakarsa. Jurnal Sains, Teknologi, Urban, Perancangan, Arsitektur (Stupa), 1(2), 941-954.

Zipjet (2017). The 2017 Global Least \& Most Stressful Cities Ranking. Retrieved January 21, 2020, from https://www.zipjet.co.uk/2017-stressful-cities-ranking 